Proceedings of the International Congress on Advances in Applied Physics and Materials Science, Antalya 2011

\title{
Influence of Annealing Temperature on the Electrical and Optical Properties of CdS Thin Films
}

\begin{abstract}
S. Elmas, S. Ozcan, S. Ozder And V. Bilgin
Physics Department, University of Canakkale Onsekiz Mart, Terzioglu Campus, 17020, Canakkale, Turkey

CdS thin films were grown onto glass substrates at the substrate temperature of $573 \pm 5 \mathrm{~K}$ by ultrasonic spray pyrolysis technique. The electrical and optical properties of the films were characterized before and after thermal annealing by using electrical resistivity measurements and UV/VIS spectrophotometer, respectively. Thermal annealing of CdS films was carried out in air ambient at various annealing temperatures from 473 to $673 \mathrm{~K}$. The variation in electrical conductivity and optical parameters such as transmittance, absorbance and energy band gap of the films with thermal annealing temperature was investigated.
\end{abstract}

PACS: 72.15.Eb, 78.20.Ci

\section{Introduction}

Cadmium sulphide (CdS), belonging to the II-VI group, is an $n$-type direct band gap semiconductor $\left(E_{\mathrm{g}}=\right.$ $2.42 \mathrm{eV})$. It is studied extensively because of its band gap, high absorption coefficient, reasonable conversion efficiency, good stability and low cost [1-3]. CdS has a wide range of technical applications such as window layer for photovoltaic solar cells, optical detectors and optoelectronic devices, thin film transistors for flat panel displays [4-6].

Knowledge of some physical properties such as optical, electrical and structural properties of CdS films is very important in many scientific and technological applications in the field of optoelectronic devices, especially photovoltaic solar cells. Hence, in this work, we report the influence of the thermal annealing temperature on the electrical resistivity, optical properties and morphology of CdS films.

\section{Experimental}

The CdS thin films were prepared by using ultrasonic spray pyrolysis (USP) system. The spraying solution consisted of a 1:1 mixture (by volume) of solutions of cadmium nitrate $\left[\mathrm{Cd}(\mathrm{NO})_{3} \cdot 4 \mathrm{H}_{2} \mathrm{O}, 0.05 \mathrm{M}\right]$ and thiourea $\left[\mathrm{CS}\left(\mathrm{NH}_{2}\right)_{2} \cdot 2 \mathrm{H}_{2} \mathrm{O}, 0.05 \mathrm{M}\right]$. It was sprayed through ultrasonic nozzle onto microscope glass substrates $\left(1 \times 1 \mathrm{~cm}^{2}\right)$ using air as the carrier gas with a pressure of $10^{5} \mathrm{~Pa}$. A total $150 \mathrm{~cm}^{3}$ solution was used and sprayed during $30 \mathrm{~min}$. The solution flow rate was fixed at $5 \mathrm{~cm}^{3} \mathrm{~min}^{-1}$ and controlled by a flowmeter. The distance between the nozzle and the substrate was maintained at $35 \mathrm{~cm}$ and the substrate temperature of $573 \mathrm{~K}$ was controlled within $\pm 5 \mathrm{~K}$ by using an iron-constantan thermocouple. After deposition, thermal annealing process in air ambient at different temperatures of 473,573 and $673 \mathrm{~K}$ for $1 \mathrm{~h}$ was performed.

The electrical resistivity measurements of the films were carried out by using Lucas Lab Pro 4-440N four- -point resistivity systems. The transmittance and absorbance spectra for all the films were recorded by a Shimadzu UV-2550 (double beam, 190-900 nm) spectrophotometer. Surface morphologies and roughness measurements were determined by atomic force microscope (AFM, Park Systems XE-70). The thickness of the films were measured by Filmetrics F20 thin film thickness measurement system and listed in Table I.

\section{Results and discussion \\ 3.1. Electrical resistivity analysis}

For the electrical characterization of the films, four-probe technique has been performed, and the electrical resistivity values listed in Table I have been calculated. The electrical resistivities of all films are high, and thermal annealing temperature has not important effect on the electrical properties of the as-deposited CdS films. To determine the electrical conductivity type of CdS films, hot-probe technique was used and it was seen that the films show $n$-type conductivity.

TABLE I

The thickness and electrical resistivities for CdS thin films as-deposited and thermally annealed.

\begin{tabular}{|c|c|c|c|}
\hline Material & $\begin{array}{c}\text { Annealing } \\
\text { temperature } \\
{[\mathrm{K}]}\end{array}$ & $\begin{array}{c}\text { Thickness } \\
\text { [nm] }\end{array}$ & $\begin{array}{c}\text { Electrical } \\
\text { resistivity } \\
{[\Omega \mathrm{cm}]}\end{array}$ \\
\hline \multirow{4}{*}{$\mathrm{CdS}$} & as-deposited & 113 & $3.793 \times 10^{5}$ \\
\hline & 473 & 118 & $5.875 \times 10^{5}$ \\
\hline & 573 & 117 & $4.409 \times 10^{5}$ \\
\hline & 673 & 121 & $5.296 \times 10^{5}$ \\
\hline
\end{tabular}

\subsection{Optical properties and energy band gap}

The wavelength dependence of the optical absorbance and transmittance spectra for the as-deposited and annealed at different temperatures CdS films in the range 
of 350-900 nm are shown in Fig. 1, measured at room temperature in air. From the absorbance spectra, it is seen that the absorbance increases with the decrease in wavelength. The sharp increase in absorbance at the wavelength $\lambda<550 \mathrm{~nm}$ is due to the onset of interband transitions at the fundamental edge.
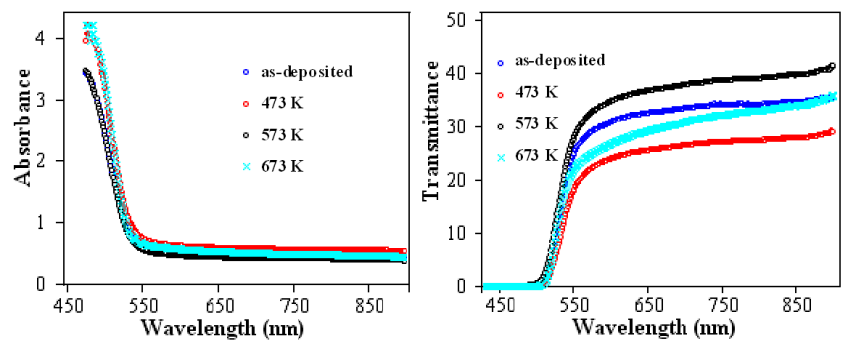

Fig. 1. Absorbance and transmittance spectra for the CdS thin films.

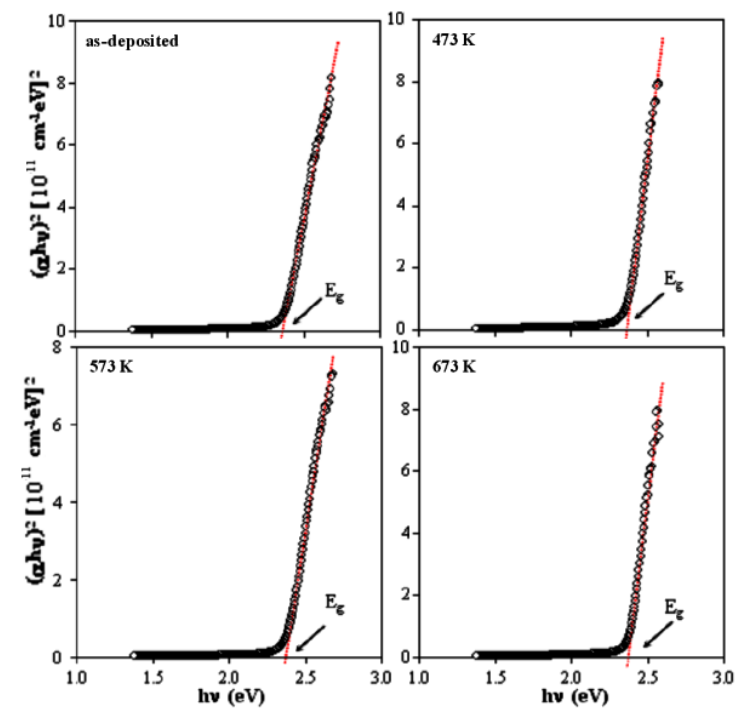

Fig. 2. The $(\alpha h v)^{2}$ versus photon energy $h v$ for the CdS thin films.

From the transmittance spectra, it is clearly seen that the average optical transmission values in the visible region for all films are low. The average optical transmittance in the wavelength region (from 550 to $900 \mathrm{~nm}$ ) of as-deposited $\mathrm{ZnO}$ thin films is about $33 \%$, while after annealing at $473 \mathrm{~K}, 573 \mathrm{~K}$, and $673 \mathrm{~K}$, the transmittance is $26 \%, 38 \%$, and $31 \%$, respectively. The transmittance is evidently increased for the films annealed at $573 \mathrm{~K}$, while decreased for other annealed films. This effect of thermal annealing on the transmission of as-deposited CdS films may be due to the some physical effects such as structural, surface irregularity, and defect density.

The absorption coefficient $(\alpha)$ was analyzed using the following expression for near-edge optical absorption of semiconductors $[7,8]$ : $\alpha h v \sim\left(h v-E_{\mathrm{g}}\right)^{1 / 2}$ (for direct band transition),

where $h v$ is the incident photon energy. To determine the band gap energy $E_{\mathrm{g}}$, the $(\alpha h v)^{2}$ versus $h v$ for all films are plotted and presented in Fig. 2. The band gap could be obtained from extrapolating the straight portion of the graph on $h v$ axis at $\alpha=0$. The determined band gap energy values are listed in Table II. The optical band gap of the as-deposited CdS films slightly increases with the thermal annealing, but this increase is not considered as important.

TABLE II

Band gap energies $\left(E_{\mathrm{g}}\right)$ and Urbach parameters $\left(E_{0}\right)$ for CdS thin films.

\begin{tabular}{l|c|c}
\hline \hline Material & $\begin{array}{c}\text { Band gap } \\
\text { energy, } \\
E_{\mathrm{g}}[\mathrm{eV}]\end{array}$ & $\begin{array}{c}\text { Urbach } \\
\text { parameter, } \\
E_{0}[\mathrm{meV}]\end{array}$ \\
\hline CdS (as-grown) & 2.38 & 133 \\
CdS (annealed at $473 \mathrm{~K})$ & 2.37 & 128 \\
CdS (annealed at $573 \mathrm{~K})$ & 2.38 & 125 \\
CdS (annealed at $673 \mathrm{~K})$ & 2.38 & 98
\end{tabular}

The absorption coefficient $\alpha$ in the low energy range generally follows the exponential law, which is given by the Pankove expression [8]. By using this expression and the slopes of the linear relationship between $\ln \alpha$ and $h v$ given in Fig. 3, the Urbach parameters $E_{0}$ for the all films were estimated, and these results are given in Table II.

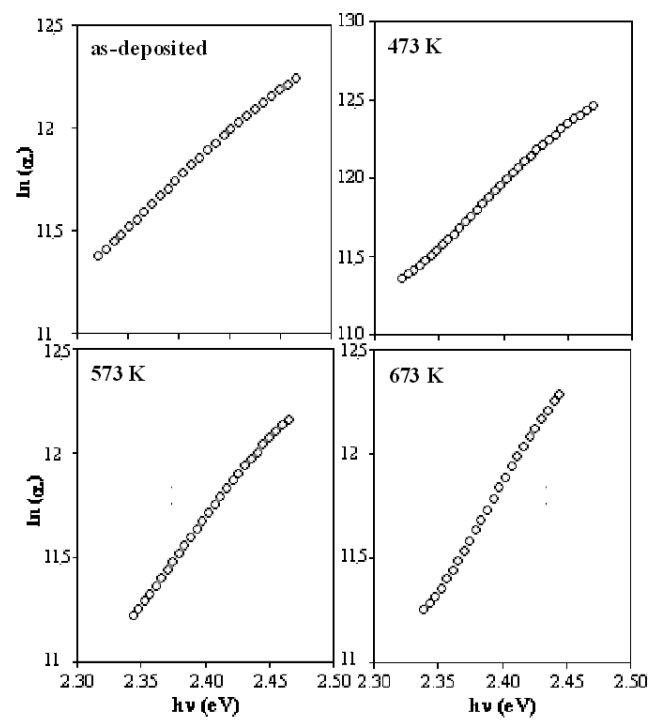

Fig. 3. The $(\ln \alpha)$ vs. $h v$ for the CdS thin films as-deposited and thermal annealed.

\subsection{Morphological characterization}

Atomic force microscopy (AFM) measurements were performed to obtain the surface roughness CdS films as-deposited and annealed at different temperatures. Figure 4 shows the AFM images with scanning area of 

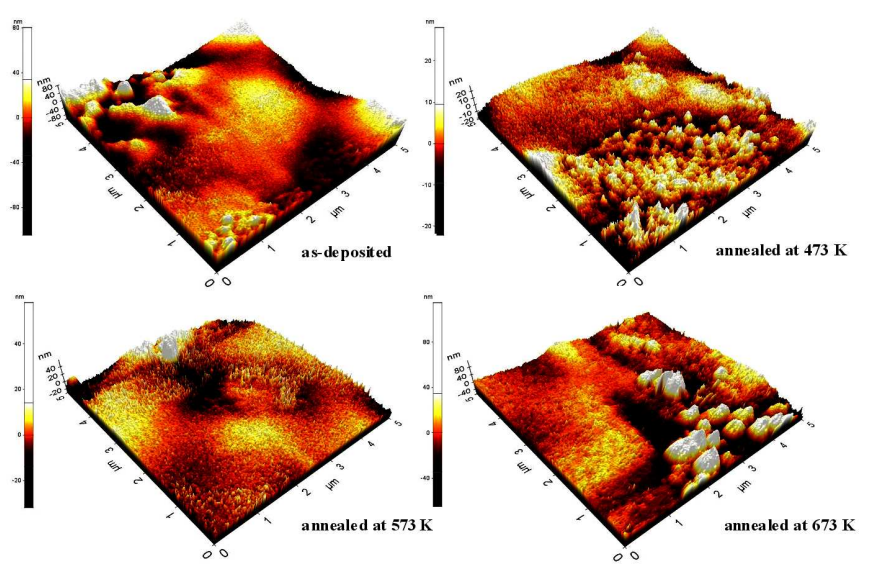

Fig. 4. The AFM images of the CdS films as-deposited and thermal annealed.

$5 \times 5 \mu \mathrm{m}^{2}$ of the films. For all the films, it is observed clearly that the numerous protruded terraces, holes, and cracks are randomly distributed on the surface of the films and their surfaces are not homogeneous. The as-deposited CdS films have a root mean square (RMS) roughness of about $12.93 \mathrm{~nm}$. For the films annealed at $473 \mathrm{~K}$ and $573 \mathrm{~K}$, the RMS roughness decreased to
$3.76 \mathrm{~nm}$ and $5.10 \mathrm{~nm}$, respectively; while for the films annealed at $673 \mathrm{~K}$ the RMS roughness inversely increased to $12.61 \mathrm{~nm}$. The surface morphology of the as-deposited CdS films appears to change significantly as a function of the thermal annealing temperature.

\section{References}

[1] N. Romeo, V. Canevari, Sol. Energy Mater Sol. Cells 58, 209 (1999).

[2] A. Kumar, S. Mital, J. Mol. Catal. A Chem. 219, 65 (2004).

[3] S.A. Al Kuhaimi, Vacuum 51, 349 (1998).

[4] S. Sarpa, D.D. Sarma, Phys. Rev. B 69, 125304 (2004).

[5] R.R. Arya, P.M. Sarro, J.J. Loferski, Appl. Phys. Lett. 41, 355 (1982).

[6] X. Duan, C. Niu, V. Sahi, J. Chen, J.W. Parce, S. Empedocles, J. Goldman, Nature 425, 274 (2003).

[7] J. Tauc, R. Grigorovich, A. Vancu, Phys. Status Solidi 15, 627 (1966).

[8] J.I. Pankove, Optical Process in Semiconductors, Solid State Physical Electronics Series, Prentice-Hall, NJ 1971, p. 422. 